\title{
Supporting Information for \\ Resolving ambient organic aerosol formation and aging pathways with simultaneous molecular composition and volatility observations
}

\author{
Ben H. Lee ${ }^{1, \dagger}$, Emma L. D'Ambro ${ }^{2,+, \neq}$, Felipe D. Lopez-Hilfiker ${ }^{1, \S}$, Siegfried Schobesberger ${ }^{1, l l}$, Claudia \\ Mohr $^{1,9}$, Maria A. Zawadowicz ${ }^{3}$, Jiumeng Liu, ${ }^{3, \#}$, John E. Shilling ${ }^{3}$, Weiwei Hu ${ }^{4,+\dagger}$, Brett B. Palm ${ }^{4, \neq \ddagger}$, Jose L. \\ Jimenez ${ }^{4}$, Liqing Hao ${ }^{5}$, Annele Virtanen ${ }^{5}$, Haofei Zhang ${ }^{6, \S \S}$, Allen H. Goldstein ${ }^{6}$, Havala O. T. Pye ${ }^{7}$, Joel A. \\ Thornton ${ }^{1, *}$ \\ ${ }^{1}$ Department of Atmospheric Sciences, University of Washington, Seattle, WA, U.S.A. \\ 2 Department of Chemistry, University of Washington, Seattle, WA, U.S.A. \\ 3 Atmospheric Sciences and Global Change Division, Pacific Northwest National Laboratory, Richland, WA, U.S.A. \\ ${ }^{4}$ Cooperative Institute for Research in Environmental Sciences and Department of Chemistry, University of \\ Colorado, Boulder, CO, U.S.A. \\ ${ }^{5}$ Department of Applied Physics, University of Eastern Finland, Kuopio, Finland. \\ 6 Department of Environmental Science, Policy, and Management, University of California, Berkel ey, CA, U.S.A. \\ 7 Office of Research and Development, Environmental Protection Agency, Research Triangle, NC, U.S.A. \\ ${ }^{\dagger}$ Equally contributing co-authors \\ F Now at the Oak Ridge Institute for Science and Education, US Environmental Protection Agency, Research \\ Triangle Park, NC, USA. \\ $\S$ Now at TofWerk AG, Thun, Switzerland. \\ II Now at University of Eastern Finland, Kuopio, Finland. \\ I Now at Stockholm University, Stockholm, Sweden. \\ \# Now at Harbin Institute of Technology, Harbin, China. \\ ${ }^{+\dagger}$ Now at Guangzhou Institute of Geochemistry, Chinese Academy of Sciences, Guangzhou, Chi na. \\ ¥¥ Now at University of Washington, Seattle, WA, U.S.A. \\ $\S \S$ Now at University of California, Riverside, CA, U.S.A.
}

Author Information

Corresponding author

Phone: 206-543-4010; Email: joelt@uw.edu; Mail: 408 ATG Building, Box 351640, University of Washington, Seattle, WA 98195

This file includes:

Pages S1-S17

Figures S1-S11

Tables S1-S2

References 

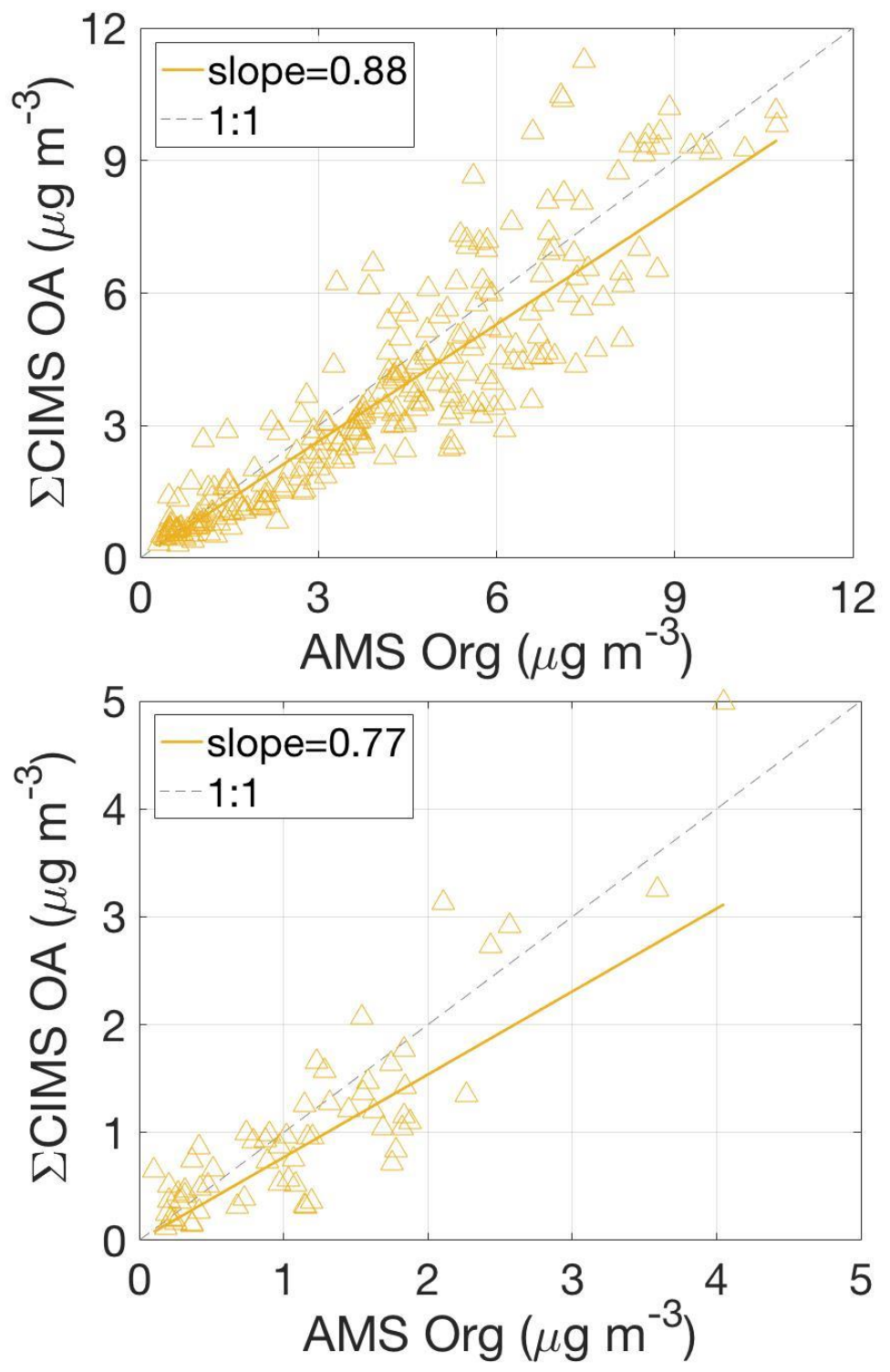

Figure S1: The sum of the masses of the 175 and 203 organic components of OA identified at (a) SOAS and (b) BAECC (as well as in the laboratory chamber experiments), plotted versus total organic aerosol mass as measured by an Aerosol Mass Spectrometer (AMS) ${ }^{1}$. We applied sensitivity values to each of the compounds given its molecular formulae according to the general trend defined by Lopez-Hilfiker et al. ${ }^{2}$. For BAECC, we present only observations during daytime (after $11 \mathrm{am}$ and before $5 \mathrm{pm}$ ) due to slow vertical mixing of air between above (FIGAERO-CIMS) and below (AMS) the forest canopy during nights. 

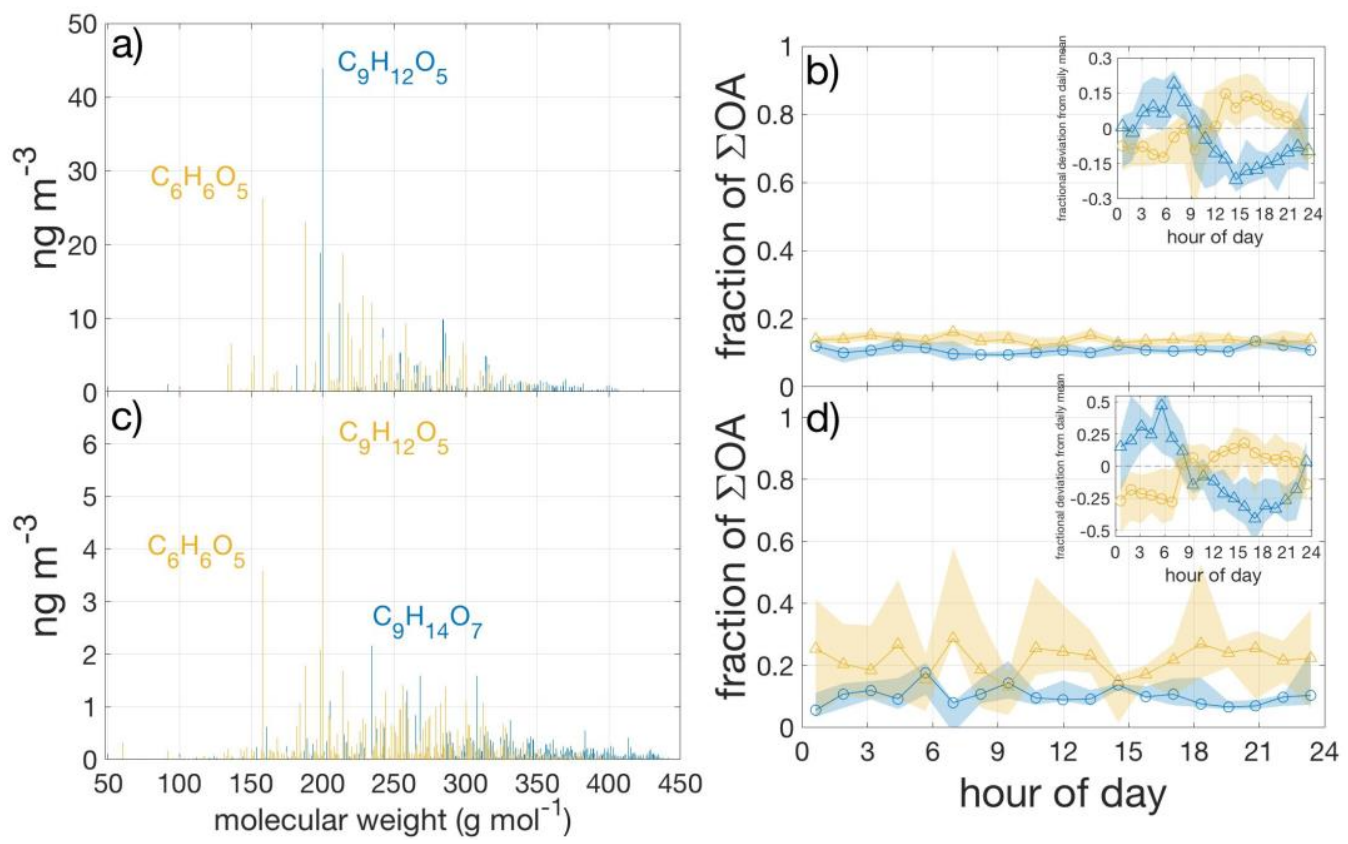

Figure S2: A total of 551 and 1018 organic compounds $\left(\mathrm{C}_{x} \mathrm{H}_{y} \mathrm{~N}_{0,1} \mathrm{O}_{z}\right)$ were identified in the FIGAERO-CIMS spectra at SOAS and BAECC, respectively,. Of these, 376 and 815 organic compounds were not identified in the laboratory chamber experiments. The sum of their masses account for on median $23 \%$ and $12 \%$ at SOAS and BAECC, respectively, of the total OA mass as measured by the AMS technique. We performed non-negative matrix factorization (NNMF) on those that were not utilized in the source apportionment. We identified two broad temporal trends at each field site; one in which the contribution of the subgroup to the total was enhanced and another at nighttime, though their diel variations were not as pronounced compared to those included in the source apportionment that contributed a larger fraction of the total OA mass. The median mass distribution of the species not utilized in the source apportionment during (a) SOAS and (c) BAECC, plotted as a function of molecular weight, along with their ( $b$ and $d$ ) diel variations. Each is colored by the NNMF-determined (gold) daytime and (blue) nighttime subgroups. The insets show the diel medians of the deviation from their respective daily mean values to better show their trends. 


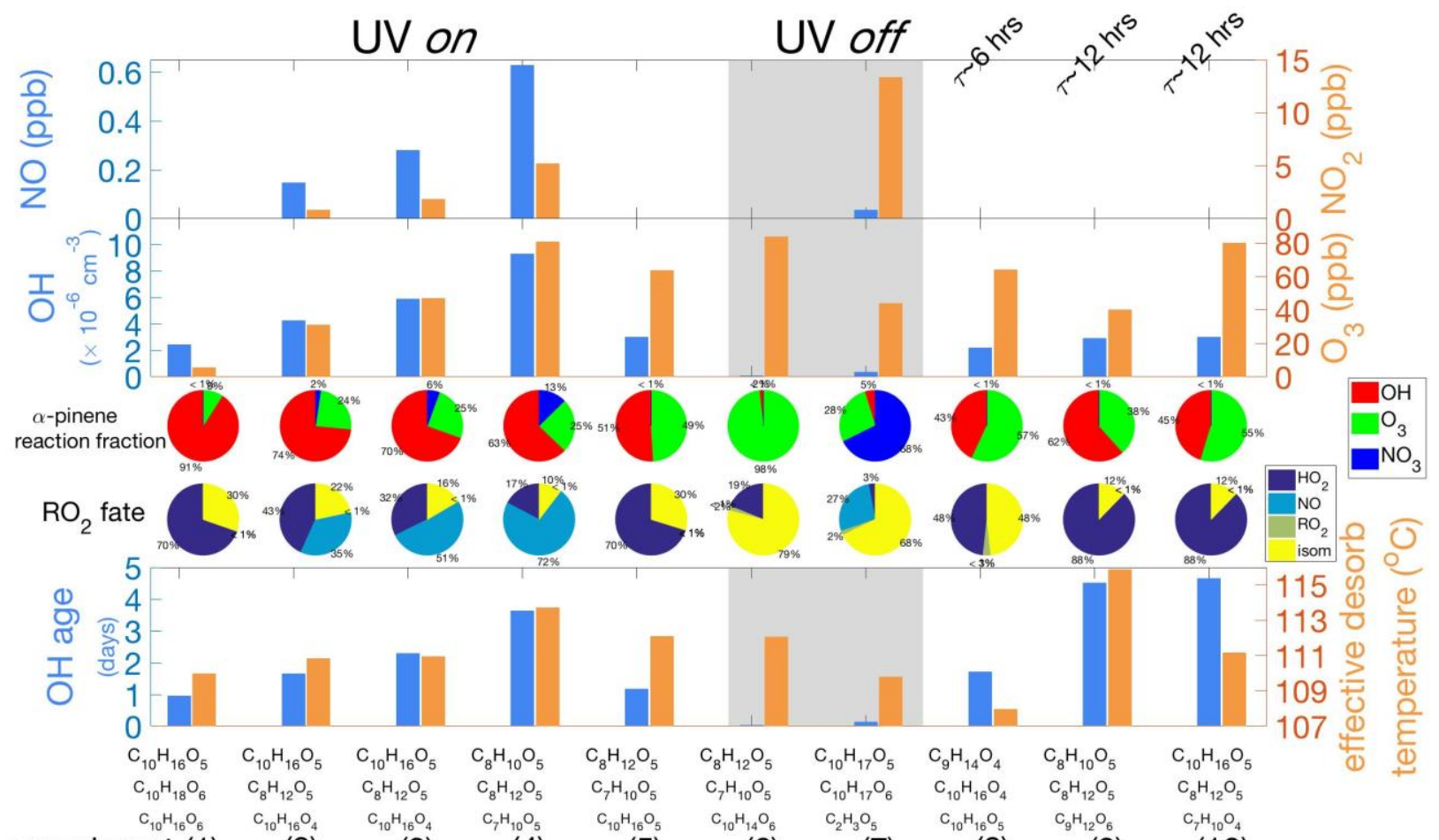
experiment (1)

(2)

(3)

(4)

(5)

(6)

(7)

(8)

(9)

(10)

Figure S3: Additional details on the 10 experiments involving monoterpene $\alpha$-pinene oxidation, corresponding to Supplementary Table 1. UV lights were on for all 10 experiments except for experiments 6 and 7. Chamber residence times (one e-folding time) was $\sim 3.5$ hours, except for experiment 8 ( $\sim 6$ hours), and experiments 9-10 ( $12 \mathrm{hrs}$ ). $\mathrm{O}_{3}$ and effective desorption temperature were directly measured. All other variables were calculated using the FOAM model (version 3$)^{3}$. Rate of $\mathrm{RO}_{2}$ auto-oxidation in these FOAM model simulations was held constant at $0.02 \mathrm{sec}^{-1}$, which we discuss in the manuscript is likely lower than actual values. Blue (gold) vertical bars correspond to the left (right) axes. 


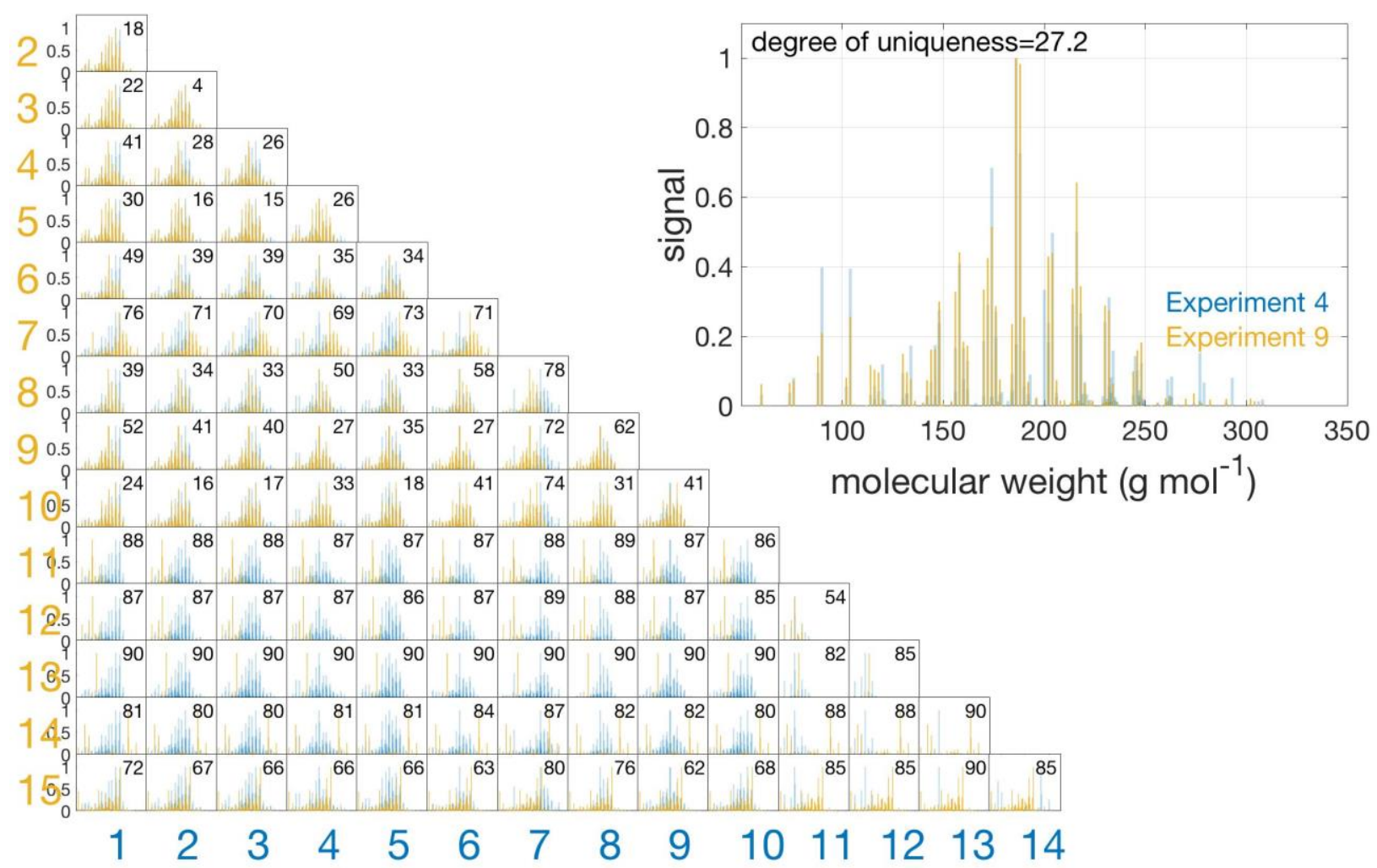

Figure S4: Cross comparis ons of the distributions of the OA components observed in 15 laboratory experiments included in the apportionment analysis. The angle of similarity is listed for each comparison, where 0 is identical and 90 is orthogonal. For instance, OA compositions observed from experiments 2 and 3 (Table S1) are similar, given the comparable chemical conditions, fate of $\mathrm{RO}_{2}$, extent of photochemical aging, etc. (Figure S3). The inset on the top right show the expanded view of the comparison of OA compositions obtained from experiments 4 and 9, the two experiments that resulted from 3.5 and 4.2 days of photochemical aging. Experiments 4 and 9 were similar (angle of similarity $=27.2$ ), but were still distinguishable, as evidenced by their distribution in carbon number space (Figure 3), by the apportionment technique. 

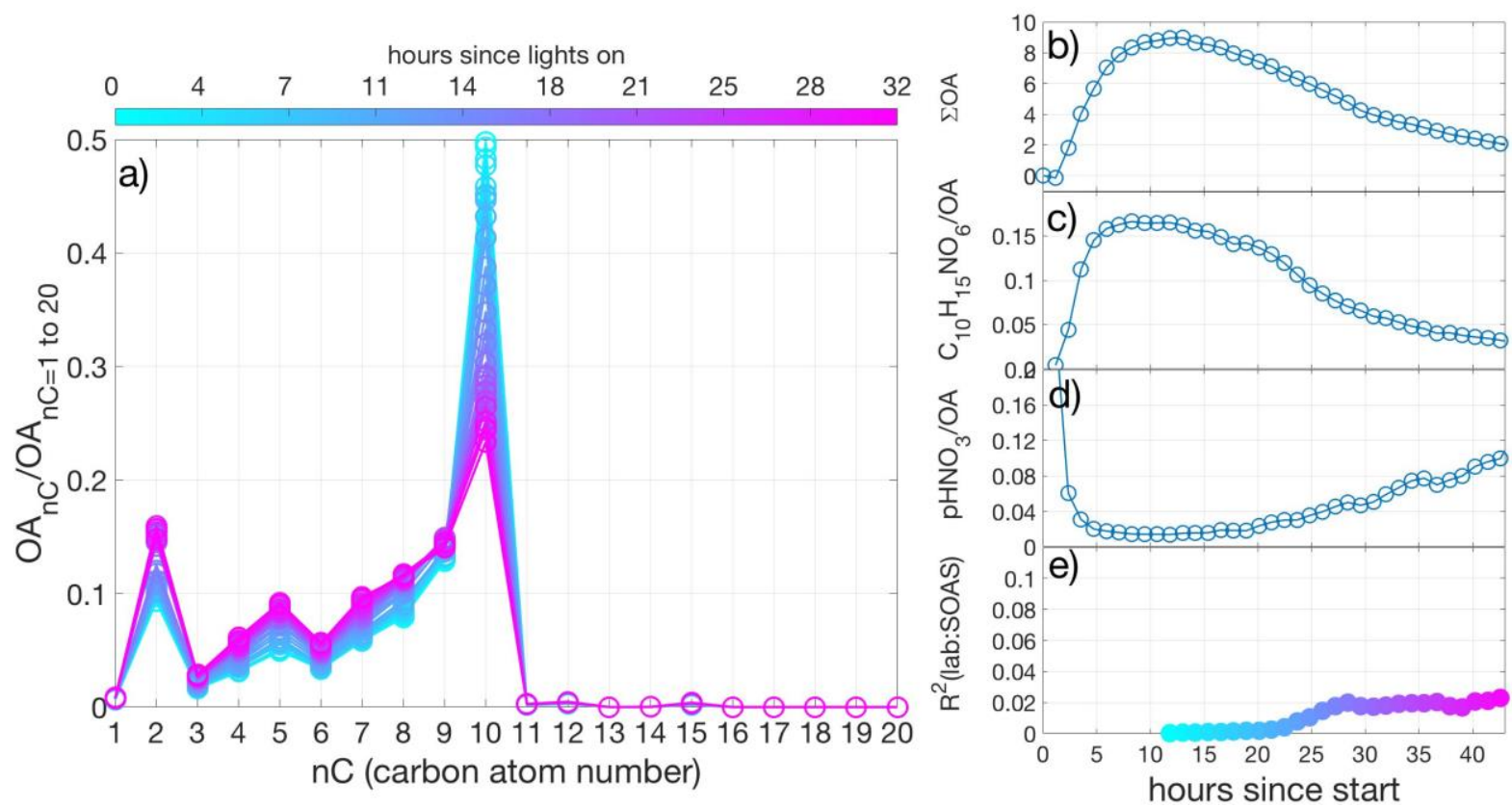

Figure S5: OA growth in batch mode experiment by oxidation of $\beta$-pinene with $\mathrm{O}_{3}$ in the presence of $\mathrm{NO}_{x}$ and absence of UV lights. (a) Distribution of OA mass as a function of carbon atom number group, colored by the experiment time, (b) evolution of total OA mass as measured by FIGAERO-CIMS in units of $\mu \mathrm{g} \mathrm{m}^{-3}$, (c) fraction of the most abundant organic nitrate, $\mathrm{C}_{10} \mathrm{H}_{15} \mathrm{NO}_{6}$, to the total OA mass, (d) fraction of particle $\mathrm{HNO}_{3}$ to total OA mass, and (e) correlation of the resulting hourly OA spectra with the median SOAS OA composition spectrum. OA growth occurred from hour zero to about the $8^{\text {th }}$ hour of the experiment, at which point, $\mathrm{OH}$ scavenger was added and UV lights were turned on. Note that $\mathrm{C}_{10} \mathrm{H}_{15} \mathrm{NO}_{6}$ decays rapidly as the particle $\mathrm{HNO}_{3}$ increases, suggestive of hydrolysis. Resulting $\mathrm{OA}$ composition (a) does not approach what is typically observed in the field (Figure 3). 

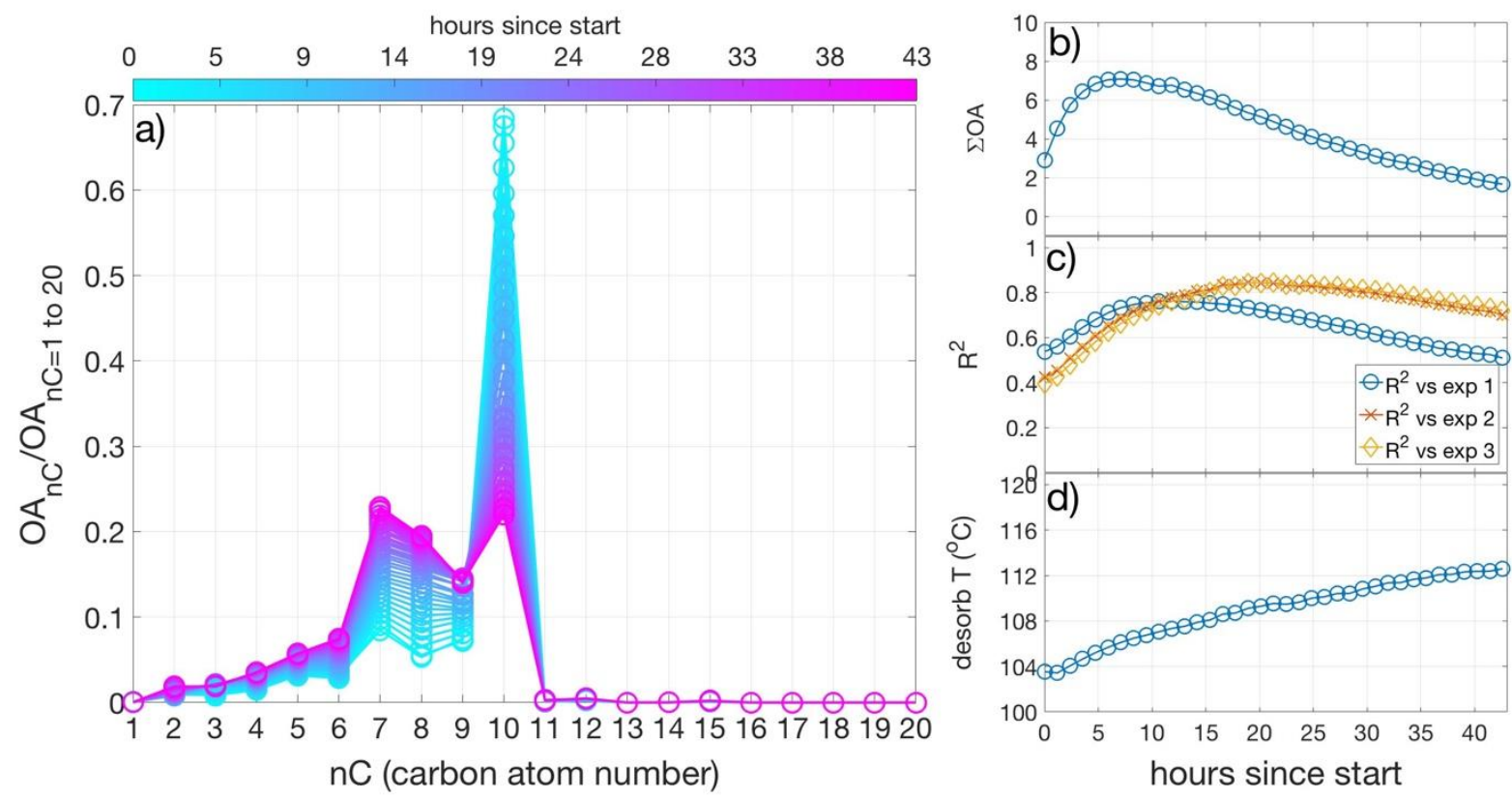

Figure S6: OA growth in batch mode experiment by oxidation of $\alpha$-pinene by $\mathrm{OH}$ with negligible $\mathrm{O}_{3}$ present. Approximately $39 \mathrm{ppb}$ of $\alpha$-pinene and $7.5 \mathrm{ppm}$ of $\mathrm{H}_{2} \mathrm{O}_{2}$ were initially injected into the chamber prior to the start of the experiment when the UV lights were turned on. (a) Distribution of OA mass as a function of carbon atom number group, colored by the experiment time, (b) evolution of total OA mass as measured by FIGAERO-CIMS in units of $\mu \mathrm{g} \mathrm{m}^{-3}$, (c) correlation of the resulting hourly OA spectra during this batch mode experiment with those of steady state exeriments 1,2 and 3 (Figure S3), all which had $f_{M T+O H} \geq 0.7$, and (d) effective volatility as measured by the characteristic desorption temperature. OA becomes less volatile with aging. Its composition is initialliy similar to that of experiment $1(\mathrm{OH}$-age of $\sim 1 \mathrm{~d}$ ) in the early stages of OA growth, then evolves to something more similar to that of experiment $2(\mathrm{OH}$ age of $\sim 1.6 \mathrm{~d})$ and experiment $3(\mathrm{OH}$-age of $\sim 2.3 \mathrm{~d})$ with continued photochemistry. This shows that the batch mode experiment reasonably duplicates the $\mathrm{OH}$-dominant conditions of experiments 1-3 in the basis set. Even with longer photochemical aging, the $\mathrm{OH}$-dominant condition is less effective at simulating ambient $\mathrm{OA}$ than with $\mathrm{OA}$ formed with $\mathrm{f}_{\mathrm{MT}+\mathrm{OH}} \sim 0.6$. For instance, $\mathrm{OH}$-dominant oxidation yields $\mathrm{OA}$ in which $\mathrm{nC}=7$ compounds are dominant, whereas $\mathrm{nC}=8$ is more prominent in the ambient and in experiments in which $\mathrm{f}_{\mathrm{MT}+\mathrm{OH}} \sim 0.6$. 


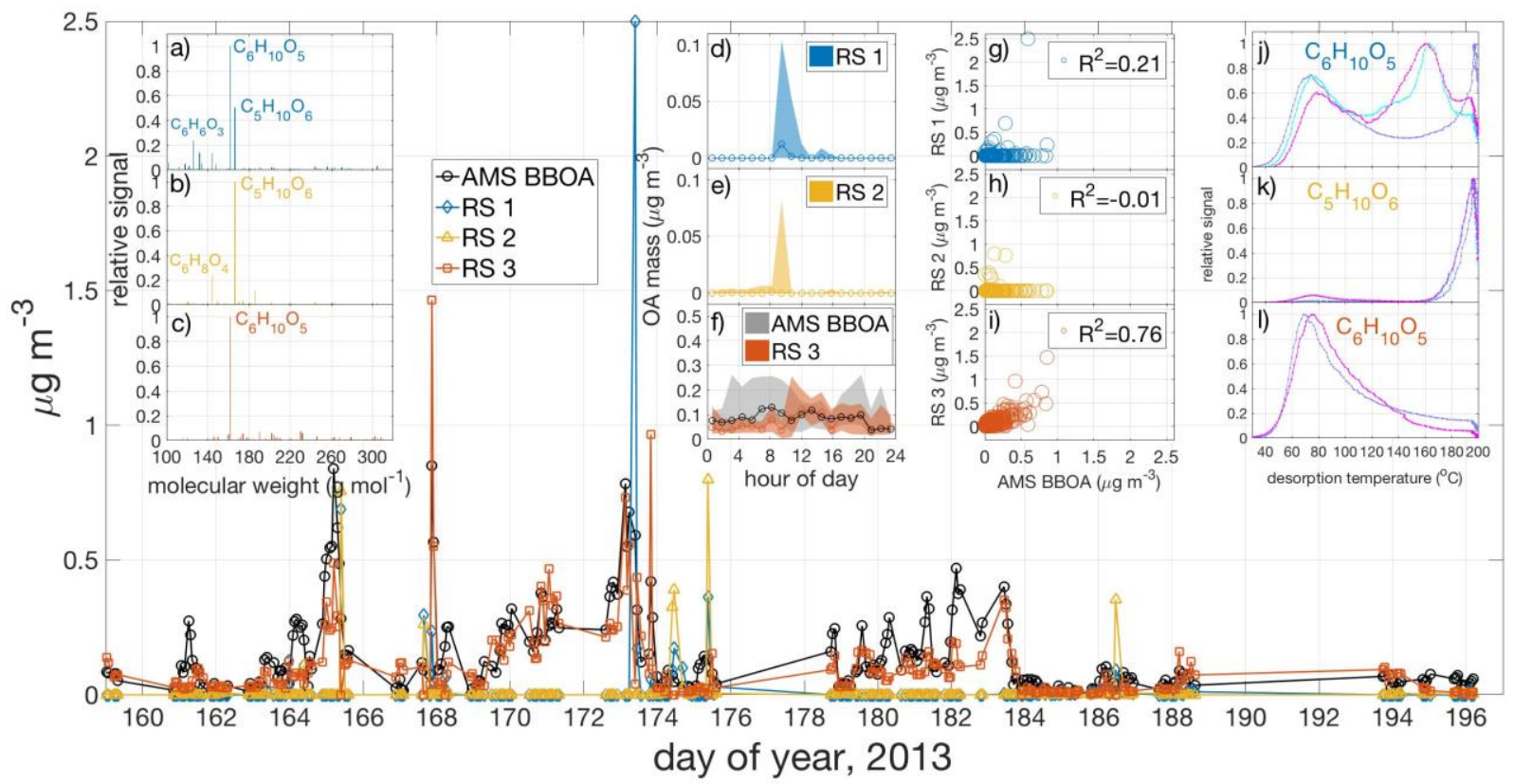

Figure S7: Time series of OA mass contributed by three (out of five) residual spectra identified from SOAS and characterized as biomass burning organic aerosol (BBOA) given the prominence of $\mathrm{C}_{6} \mathrm{H}_{10} \mathrm{O}_{5}$, presumably levoglucosan, a known byproduct of biomass combustion ${ }^{4}$. BBOA as determined by Positive Matrix Factorization of the spectra recorded by the $\mathrm{AMS}^{4}$ is also shown in the main time series. The insets $(\mathrm{a}-\mathrm{c})$ show the OA mass distribution as a function of molecular weight, (d-f) diurnal median $\pm 25^{\text {th }} / 75^{\text {th }}$ percentile as a function of hour of day, (g-i) comparison to BBOA as determined by the AMS/PMF approach, and ( $j-1)$ three normalized desorption profiles of the most abundant compound in a given residual spectrum when its contribution to the total OA mass was the greatest during SOAS. OA mass accounted for by the third residual spectrum exhibited the highest degree of correlation with AMS/PMF BBOA, and also had the highest effective OA volatility compared to those of the first two residual spectra. The two and one mass spectra from SOAS and BAECC, respectively, labeled as "other" is not shown. Its diurnal trend is shown in Figure 4. 


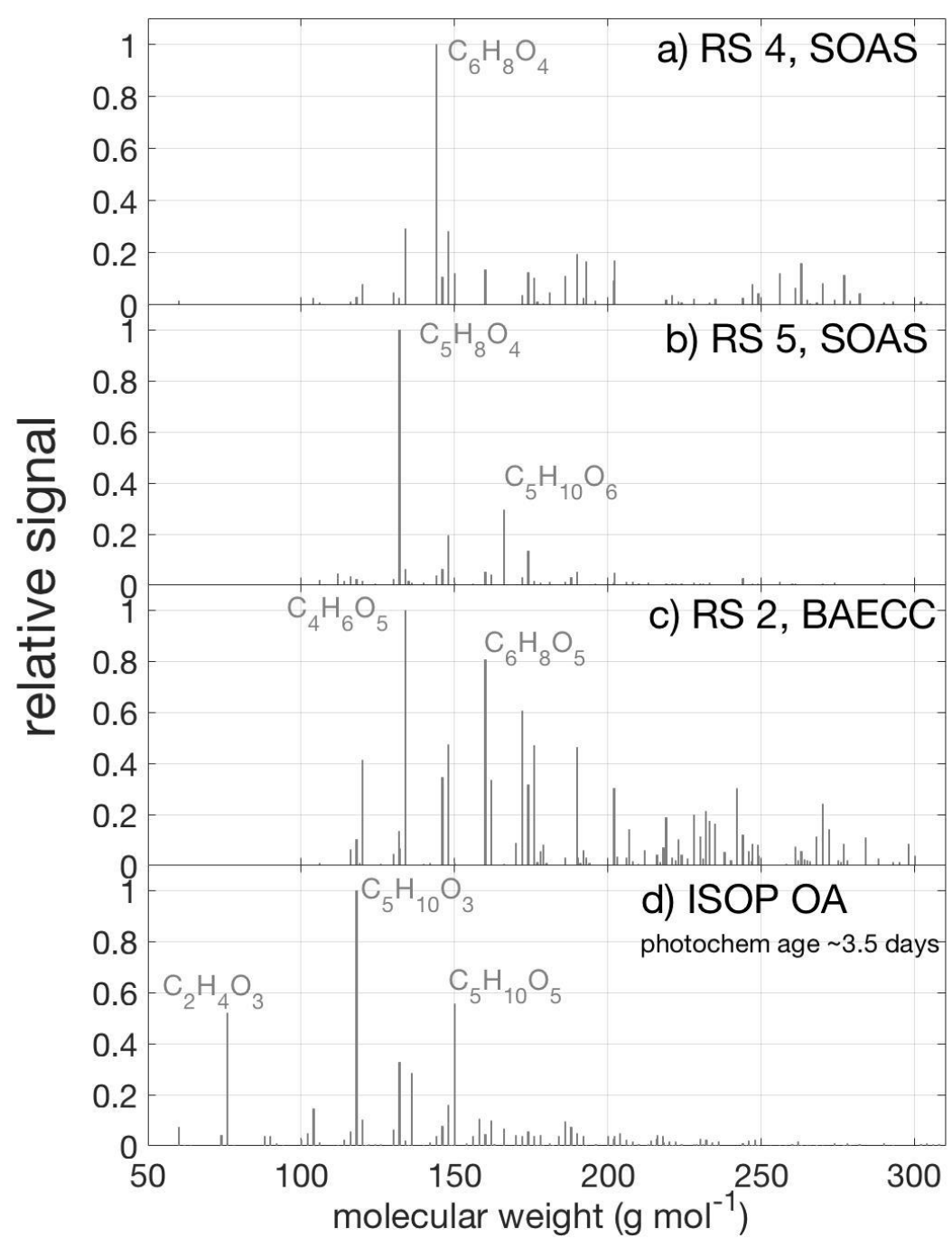

Figure S8: OA spectra of two of the five residuals for SOAS that were included in the basis set, along with one of two residuals for BAECC. The other BAECC residual spectrum is similar to residual spectrum \#3 (RS3) of SOAS (figure S7) in that it is dominated by $\mathrm{C}_{6} \mathrm{H}_{10} \mathrm{O}_{5}$, presumably levoglucosan ${ }^{4}$. Though the contribution of these residual spectra to their respective composites are enhanced during daytime (Figures $4 \mathrm{~g}$ and $4 \mathrm{~h}$ ), the distributions of OA compounds are non consistent with that of long-aged isoprene-derived OA. The origin and history of these residuals are currently unknown. 


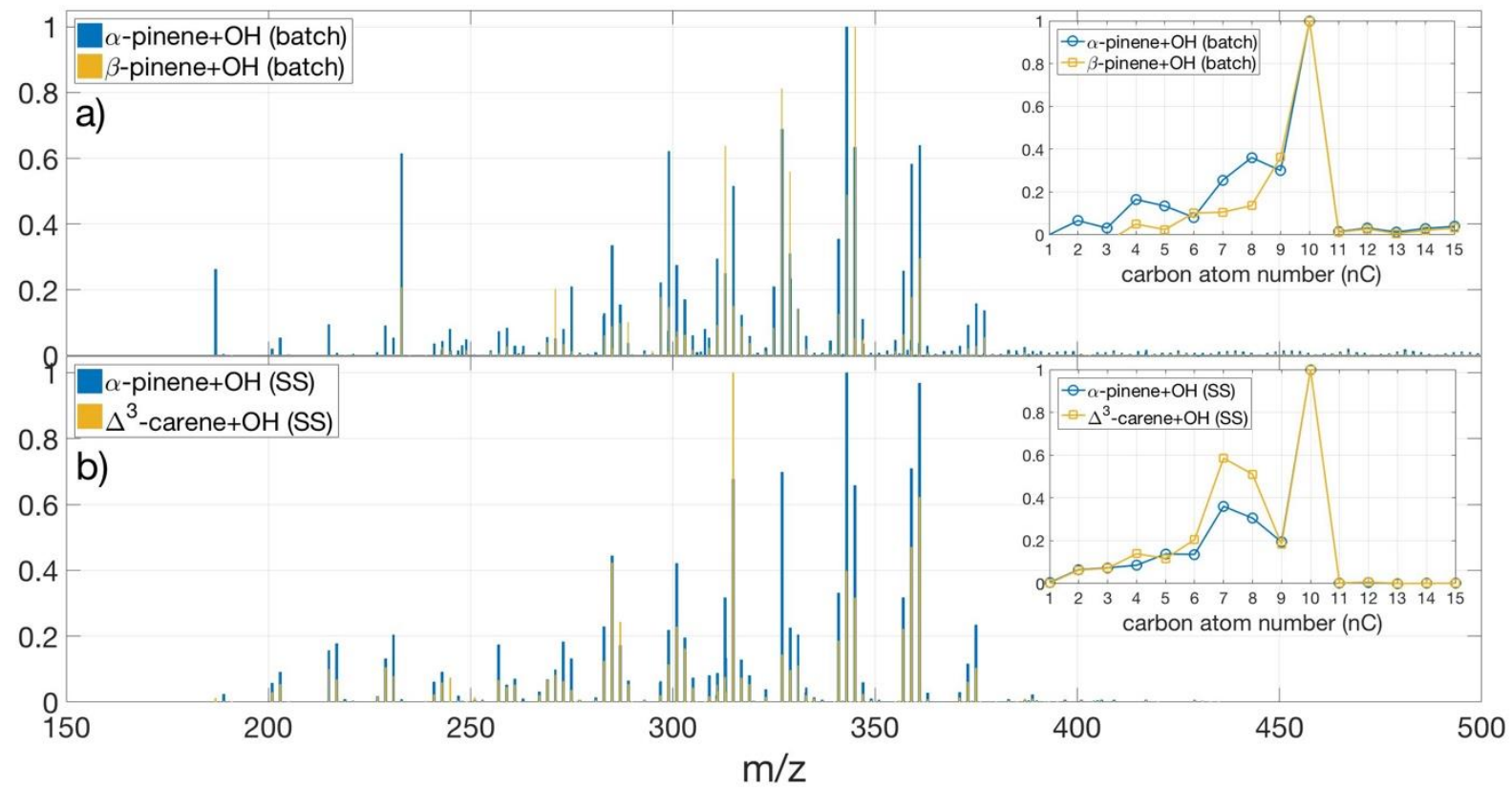

Figure S9: (a) OA mass spectra as measured by FIGAERO-CIMS of $\alpha$-pinene and $\beta$-pinene oxidation in the presence of $\mathrm{OH}$ and $\mathrm{O}_{3}$ in batch mode operation. The $\alpha$-pinene and $\beta$-pinene experiments were conducted separately under similar chemical conditions. (b) OA mass spectrum of $\alpha$-pinene and $\Delta-3$ carene oxidation in the presence of $\mathrm{OH}$ and $\mathrm{O}_{3}$ in steady state mode operation. The insets in (a) and (b) show the distribution of their respective OA composition as a function of carbon atom number. 

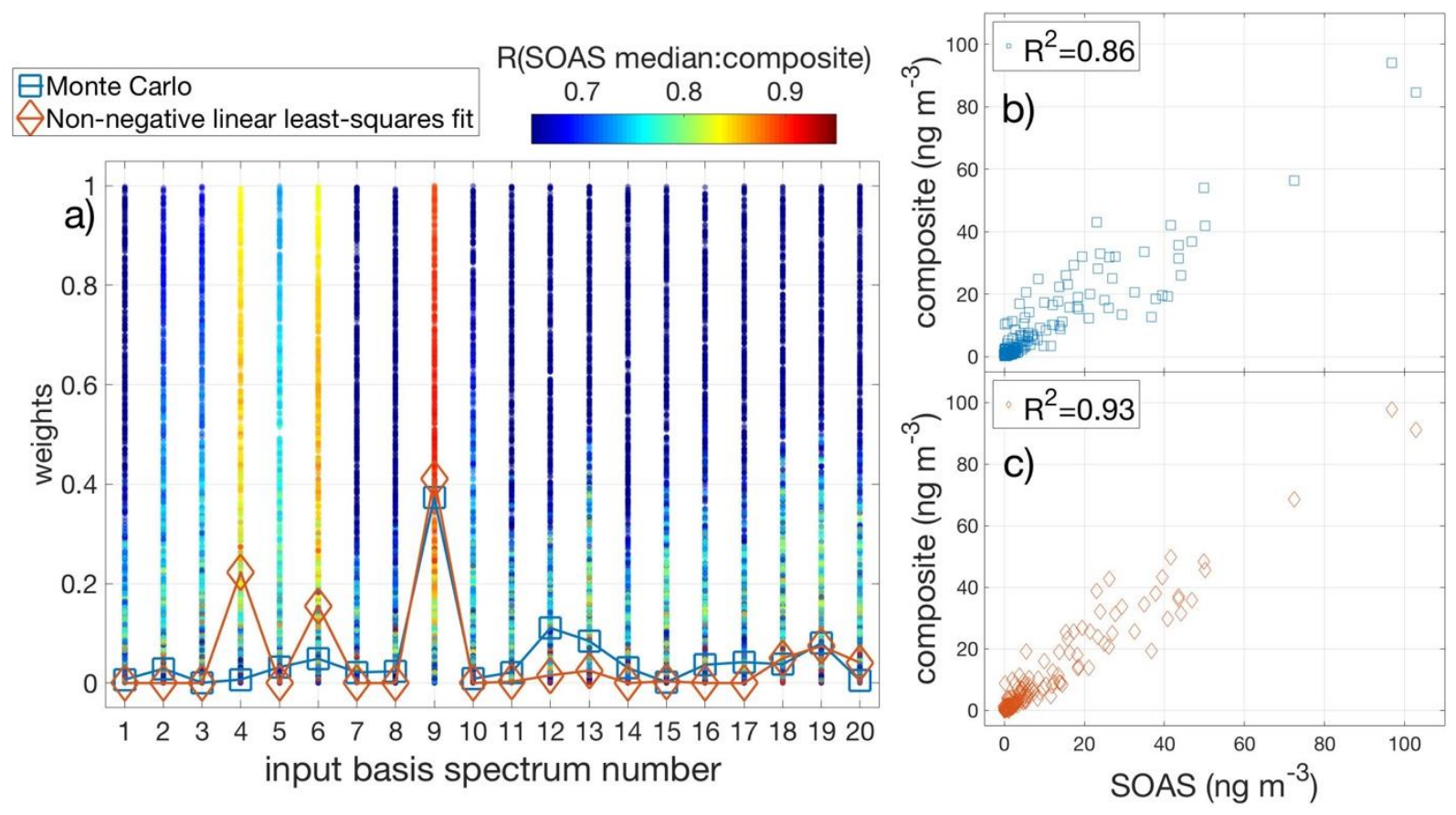

Figure S10: (a) Optimal weights of each of the 20 input basis spectra for SOAS determined by the Monte Carlo technique and the non-negative linear least-squares technique. The colored circle markers in the background of (a) represent each of the 10,000 simulations in which each of the 20 input spectra were assigned a randomized weight, all together summing up to one. The colors of those markers in (a) represent the correlation between the median SOAS distribution of $175 \mathrm{OA}$ components and that resulting from the Monte Carlo simulation. Note, the Monte Carlo-derived composite versus field-observed agreement improves as spectrum 9 is given a higher weight, and to lesser extents to spectra 4 and 6 . However, the composite spectrum that yielded the best agreement from this set of 10,000 simulations (b) was still inferior to the $(c)$ the non-negative linear least-squares technique. 

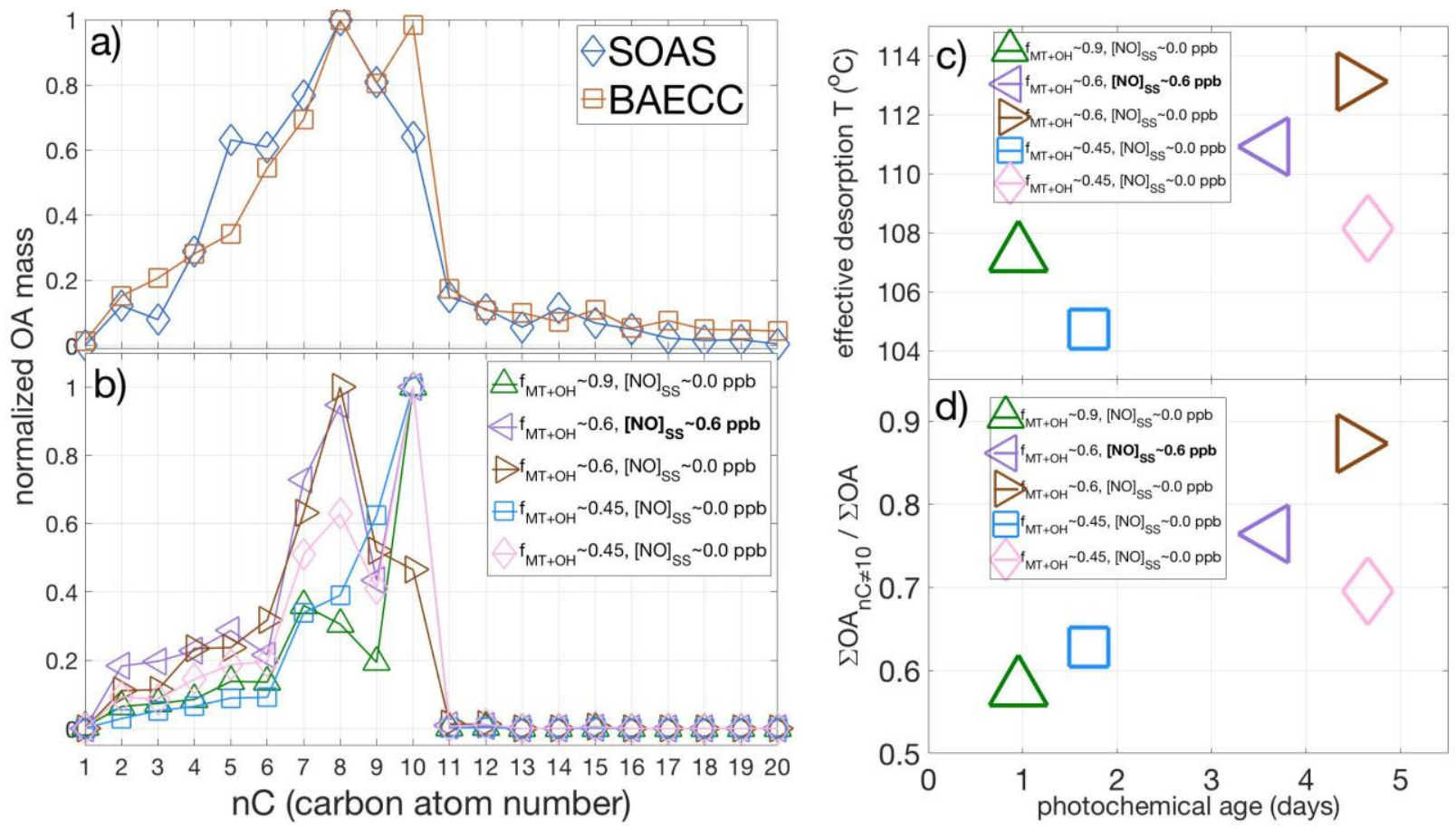

Figure S11: Fraction of OA mass contributed by each carbon atom number group (nC) during (a) SOAS and BAECC, and (b) in five photo-oxidation chamber experiments involving $\alpha$-pinene that spanned a range of $\mathrm{f}_{\mathrm{MT}+\mathrm{OH}}$ and photochemical ages. The effective desorption temperatures of the resulting OA generally increased with longer photochemical ages, as shown in (c). Also, the fraction of OA composed of compounds with less than 10 carbon atoms increased with longer photochemical ages, as shown in (d). The two effects were less pronounced for OA derived from experiment in which the $\mathrm{f}_{\mathrm{MT}+\mathrm{OH}} \sim 0.45$ compared to those in which $\mathrm{f}_{\mathrm{MT}+\mathrm{OH}} \sim 0.6$. Markers in (b), (c) and (d) represent the same experiments. 
Table S1: Additional details on the 10 laboratory experiments involving $\alpha$-pinene included in the basis set, including photochemical aging for those in which $\mathrm{OH}$ radicals were generated in significant quantities (experiments 6 and 7 were conducted without UV lights), campaign median fractions contributed to total OA mass, and the effective molecular formulae. The order of these experiments correspond to that shown on Figure S4.

\begin{tabular}{|c|c|c|c|c|c|c|c|c|c|}
\hline $\begin{array}{c}\text { Exp. } \\
\#\end{array}$ & $\begin{array}{c}\text { VOC } \\
\text { precursor }\end{array}$ & $\begin{array}{c}\text { photochemical } \\
\text { age } \\
\text { (days) }\end{array}$ & $\begin{array}{c}\text { median } \\
\text { fraction } \\
\text { contributed } \\
\text { to total OA } \\
\text { mass during } \\
\text { SOAS / } \\
\text { BAECC }\end{array}$ & $\begin{array}{l}\text { effective molecular } \\
\text { formulae } \\
\mathrm{C}_{x} \mathrm{H}_{\mathrm{y}} \mathrm{O}_{z} \mathrm{~N}_{\mathrm{a}}\end{array}$ & $\begin{array}{l}\text { Chamber } \\
\text { residence time } \\
\text { (hours) }\end{array}$ & $\begin{array}{c}\text { fraction of } \\
\text { monoterpenes } \\
\text { reacting with } \mathrm{OH}\end{array}$ & $\begin{array}{c}\mathrm{O}_{3} \\
(\mathrm{ppb})\end{array}$ & $\frac{\mathrm{OH}}{\left(\text { molecules } \mathrm{cm}^{-3}\right)}$ & $\begin{array}{l}\mathrm{NO} \\
\mathrm{NO}_{2} \\
(\mathrm{ppb})\end{array}$ \\
\hline 1 & $\alpha$-pinene & 0.96 & $0 / 0$ & $\mathrm{C}_{8.02} \mathrm{H}_{12.30} \mathrm{O}_{5.02} \mathrm{~N}_{0.00}$ & 3.5 & $\geq 0.91$ & 5 (not added) & $2.4 \times 10^{6}$ & $\begin{array}{l}0 \\
0\end{array}$ \\
\hline 2 & $\alpha$-pinene & 1.65 & $0 / 0$ & $\mathrm{C}_{7.94} \mathrm{H}_{11.98} \mathrm{O}_{5.11} \mathrm{~N}_{0.05}$ & 3.5 & 0.74 & 31 & $4.2 \times 10^{6}$ & $\begin{array}{l}0.15 \\
0.82\end{array}$ \\
\hline 3 & $\alpha$-pinene & 2.30 & $0 / 0$ & $\mathrm{C}_{7.92} \mathrm{H}_{11.93} \mathrm{O}_{5.13} \mathrm{~N}_{0.07}$ & 3.5 & 0.70 & 47 & $5.9 \times 10^{6}$ & $\begin{array}{c}0.28 \\
1.8\end{array}$ \\
\hline 4 & $\alpha$-pinene & 3.64 & $0.17 / 0.22$ & $\mathrm{C}_{7.41} \mathrm{H}_{10.81} \mathrm{O}_{5.24} \mathrm{~N}_{0.10}$ & 3.5 & 0.63 & 81 & $9.3 \times 10^{6}$ & $\begin{array}{c}0.63 \\
5.2\end{array}$ \\
\hline 5 & $\alpha$-pinene & 1.16 & $0 / 0$ & $\mathrm{C}_{7.78} \mathrm{H}_{11.56} \mathrm{O}_{4.92} \mathrm{~N}_{0.00}$ & 3.5 & 0.51 & 64 & $3.0 \times 10^{6}$ & $\begin{array}{l}0 \\
0\end{array}$ \\
\hline 6 & $\alpha$-pinene & NA & $0.10 / 0.08$ & $\mathrm{C}_{7.72} \mathrm{H}_{11.26} \mathrm{O}_{5.10} \mathrm{~N}_{0.00}$ & 3.5 & 0.02 & 84 & $0.07 \times 10^{6}$ & $\begin{array}{l}0 \\
0\end{array}$ \\
\hline 7 & $\alpha$-pinene & NA & $0 / 0.20$ & $\mathrm{C}_{8.34} \mathrm{H}_{12.56} \mathrm{O}_{5.88} \mathrm{~N}_{0.61}$ & 3.5 & 0.05 & 44 & $0.3 \times 10^{6}$ & $\begin{array}{l}0.04 \\
13.4\end{array}$ \\
\hline 8 & $\alpha$-pinene & 1.70 & $0 / 0$ & $\mathrm{C}_{8.34} \mathrm{H}_{13.13} \mathrm{O}_{4.78} \mathrm{~N}_{0.00}$ & 6 & 0.43 & 64 & $2.2 \times 10^{6}$ & $\begin{array}{l}0 \\
0\end{array}$ \\
\hline
\end{tabular}




\begin{tabular}{c|c|c|c|c|c|c|c|c}
9 & $\alpha$-pinene & 4.51 & $0.29 / 0.15$ & $\mathrm{C}_{7.30} \mathrm{H}_{10.34} \mathrm{O}_{5.18} \mathrm{~N}_{0.01}$ & 12 & 0.62 & 40 & $2.9 \times 10^{6}$ \\
\hline 10 & $\alpha$-pinene & 4.65 & $0 / 1 \times 10^{-4}$ & $\mathrm{C}_{7.84} \mathrm{H}_{11.96} \mathrm{O}_{4.85} \mathrm{~N}_{0.01}$ & 12 & 0.45 & 80 & 0 \\
0
\end{tabular}


Table S2: OA apportionment results using CMAQ v5.3.

\begin{tabular}{|c|c|c|c|}
\hline Description & label & $\begin{array}{l}\text { Fractional } \\
\text { contributions to total } \\
\text { OA at } \\
\text { SOAS / BAECC }\end{array}$ & raw model species from v5.3 \\
\hline Prompt monoterpene SOA & MTSOA & $0.48 / 0.25$ & $\begin{array}{c}\text { AMT1J[1]+AMT2J[1]+AMT3J[1]+ } \\
\text { AMT4J[1]+AMT5J[1]+AMT6J[1] (from OH and O3 only) }\end{array}$ \\
\hline $\begin{array}{l}\text { Particulate organic nitrates from } \\
\text { monoterpene oxidation }\end{array}$ & MTORGNO3 & $0.03 / 0.04$ & AMTNO3J[1] \\
\hline $\begin{array}{l}\text { Hydrolysis products of particulate } \\
\text { organic nitrates }\end{array}$ & MTHYDROLYSIS & $0.07 / 0.11$ & AMTHYDJ[1] \\
\hline IEPOX SOA & IEPOXSOA & $0.02 / 0.04$ & AISO3J[1] \\
\hline $\begin{array}{l}\text { Non-IEPOX Isoprene SOA (from } \\
\text { isop+NO3 and semivolatile } \mathrm{OH} \\
\text { products) }\end{array}$ & ISOPSOA & $0.03 / 0.01$ & AISO1J[1]+AISO2J[1] \\
\hline Sesquiterpene SOA & SESQSOA & $0.15 / 0.04$ & ASQTJ[1] \\
\hline Biogenic oligomers & BIOGOLIG & $0.11 / 0.07$ & $\begin{array}{c}\text { AOLGBJ[1] (only from ISOPSOA, SESQSOA, not } \\
\text { monoterpenes) }\end{array}$ \\
\hline $\begin{array}{l}\text { Glyoxal+MGLY SOA (aqueous } \\
\text { aerosol and in-cloud) }\end{array}$ & GLYSOA & $0.06 / 0.06$ & AGLYJ[1]+AORGCJ[1] \\
\hline Primary OA & POA & $0.03 / 0.22$ & $\begin{array}{l}\text { ALVPO1I[1] + ASVPO1I[1] + ASVPO2I[1] + ALVPO1J[1] + } \\
\text { ASVPO1J[1] + ASVPO2J[1] + ASVPO3J[1] + AIVPO1J[1] }\end{array}$ \\
\hline $\begin{array}{l}\text { Anthropogenic SOA (BTX, alkanes, } \\
\text { PAHs, oligomers, oxidized SVOCs) }\end{array}$ & ANTHROSOA & $0.02 / 0.15$ & $\begin{array}{c}\text { ALVOO1I[1] + ALVOO2I[1] + ASVOO1I[1] + ASVOO2I[1] } \\
+ \text { AAVB1J[1] + AAVB2J[1] + AAVB3J[1] + AAVB4J[1] + } \\
\text { ALVOO1J[1] + ALVOO2J[1] + ASVOO1J[1] + ASVOO2J[1] + } \\
\text { ASVOO3J[1] +AOLGAJ[1] }\end{array}$ \\
\hline
\end{tabular}



CMAQ) 


\section{References}

1. Jayne, J. T.; Leard, D. C.; Zhang, X. F.; Davidovits, P.; Smith, K. A.; Kolb, C. E.;

Worsnop, D. R., Development of an aerosol mass spectrometer for size and composition analysis of submicron particles. Aerosol Sci Tech 2000, 33 (1-2), 49-70.

2. $\quad$ Lopez-Hilfiker, F. D.; Iyer, S.; Mohr, C.; Lee, B. H.; D'Ambro, E. L.; Kurten, T.; Thornton, J. A., Constraining the sensitivity of iodide adduct chemical ionization mass spectrometry to multifunctional organic molecules using the collision limit and thermodynamic stability of iodide ion adducts. Atmos Meas Tech 2016, 9 (4), 1505-1512.

3. Wolfe, G. M.; Thornton, J. A., The Chemistry of Atmosphere-Forest Exchange (CAFE) Model - Part 1: Model description and characterization. Atmos Chem Phys 2011, 11 (1), 77-101.

4. Simoneit, B. R. T.; Schauer, J. J.; Nolte, C. G.; Oros, D. R.; Elias, V. O.; Fraser, M. P.; Rogge, W. F.; Cass, G. R., Levoglucosan, a tracer for cellulose in biomass burning and atmospheric particles. Atmos Environ 1999, 33 (2), 173-182. 